\title{
PERFIL FÍSICO-QUÍMICO E MICROBIOLÓGICO DE ÁGUAS MINERAIS COMERCIALIZADAS NO MUNICÍPIO DE MARABÁ - PARÁ
}

\section{PROFILE PHYSICAL-CHEMICAL AND MICROBIOLOGICAL THE MINERAL WATER IN THE CITY OF MARKETED MARABÁ - PARÁ}

\author{
Mariane Freitas Galvão ${ }^{1}$; Phâmela Aparecida Santos Silva ${ }^{2}$; Elaine Lopes Figueiredo ${ }^{3}$ \\ ${ }^{1}$ Universidade do Estado do Pará - UEPA - Belém - Brasil malane_8@ hotmail.com \\ ${ }^{2}$ Universidade do Estado do Pará - UEPA - Belém - Brasil phamelasantos@ hotmail.com \\ ${ }^{3}$ Universidade do Estado do Pará - UEPA - Belém - Brasil lane figueiredo@yahoo.com.br
}

\begin{abstract}
Resumo
As águas minerais são provenientes das fontes subterrâneas que se originam através da infiltração da água no solo a partir da superfície, que se enriqueceram em sais minerais. Devem apresentar caracteristicas físico-químicas e qualidade microbiológica adequadas ao consumo humano, sendo considerada de suma importância para a saúde. Existe uma grande preocupação por parte dos consumidores com a qualidade da água que se consome. Assim, este trabalho objetivou avaliar as características físico-químicas ( $\mathrm{pH}$, alcalinidade, dureza total, turbidez, sólidos totais, cor e cloretos) e microbiológicas (coliformes totais, coliformes termotolerantes, Pseudomonas aeroginosas e Clostridium sulfito redutores) de três marcas de águas minerais comercializadas no município de Marabá-Pará. Os resultados das análises físico-químicas demonstraram que as amostras de água, estão dentro dos padrões estabelecidos pelas legislações vigentes. Porém, as amostras $A$ e $B$ foram consideradas reprovadas em relação ao nível de $\mathrm{pH}$, com valores de 5,20 e 4,63 , respectivamente. Os resultados microbiológicos identificaram que todas as marcas de água encontram-se dentro dos padrões microbiológicos estabelecidos pela legislação, apresentando ausência de todos os micro-organismos avaliados.
\end{abstract}

Palavras-chave: água mineral, qualidade, saúde.

\section{Introdução}

Segundo o art. $1^{\circ}$ do Código de Águas Minerais, estas "são aquelas provenientes de fontes naturais ou de fontes artificiais captadas, que possuam composição química ou propriedades físicas ou físico-químicas distintas das águas comuns, características que lhe confiram uma ação medicamentosa" (BRASIL, 2005).

A Comissão Nacional de Normas para Alimentos acrescentou à definição a frase "de origem profunda, não sujeitas à influência de águas superficiais". Podem ser consideradas minerais as 
águas de origem profunda que, mesmo sem atingir os limites da classificação estabelecida naqueles padrões, possuam comprovada propriedade favorável à saúde, mediante observações de ordem clínica e farmacológica, e aprovada pelo órgão federal de saúde competente (POMPEU, 2010).

Segundo a Resolução de Diretoria Colegiada - RDC, nº 275, de 22 de setembro de 2005, da Agência Nacional de Vigilância Sanitária (ANVISA), as águas minerais são caracterizadas pelo conteúdo definido e constante de sais minerais e pela presença de oligoelementos e outros constituintes. Além disso, não podem produzir, desenvolver e/ou agregar substâncias físicas, químicas ou biológicas que coloquem em risco a saúde do consumidor e/ou alterem a composição original do produto (BRASIL, 2005).

A água para consumo humano e uso na indústria de alimentos deve atender aos padrões físicos, químicos e microbiológicos estabelecidos na legislação brasileira, de acordo com a Portaria $n^{\circ} 518$, do Ministério da Saúde, publicada em 25 de março de 2004 (ANDRADE, 2008).

Para o consumo humano, há a necessidade de uma água pura e saudável, isto é, livre de matéria suspensa visível, cor, gosto e odor, de quaisquer organismos capazes de provocar enfermidades e de quaisquer substâncias orgânicas ou inorgânicas que possam produzir efeitos fisiológicos prejudiciais (RICHTER; NETTO, 1991).

Os parâmetros químicos são os índices mais importantes para se caracterizar a qualidade da água. Estes parâmetros permitem classificá-las por seu conteúdo mineral, através dos íons presentes; determinar o grau de contaminação, permitindo determinar a origem dos principais poluentes; caracterizar picos de concentração de poluentes tóxicos e as possíveis fontes; e avaliar o equilíbrio bioquímico que é necessário para a manutenção da vida aquática, permitindo avaliar as necessidades de nutrientes (BRANCO, 1999; MACÊDO, 2001).

Existe uma percepção de que o consumo de água mineral natural está relacionado a um estilo de vida saudável e que estes produtos são relativamente seguros. Entretanto, a ocorrência de distúrbios gastrintestinais seguintes ao consumo destas águas tem focado atenção ao estudo de sua microbiologia. Sua contaminação pode ocorrer na fonte, no envase (devido a natureza do processo ou a reutilização de recipiente não devidamente higienizado), e no transporte e armazenamento, no caso da embalagem não ser absolutamente estanque (SILVA et al., 2008).

$\mathrm{Na}$ análise ou monitoramento de qualidade de água são empregados indicadores biológicos específicos. Os coliformes, bastonetes gram-negativos da família Enterobacteraceae, são os indicadores mais comumente empregados ao estudo de qualidade de água. Amplamente distribuídos na natureza se propagam com maior freqüência na água, especialmente, os coliformes fecais, que têm tido grande atenção da saúde pública, por estarem associados a um elevado número de patologias. Além de infecções intestinais, podem estar envolvidos ou ter participação em diversas outras patologias (meningites, intoxicações alimentares, infecções urinárias e pneumonias 
nosocomiais) (ANDRADE, 2008; SILVA et al., 2008).

Assim, este trabalho tem como objetivo avaliar as caracterísiticas físico-químicas e microbiológicas de três marcas de água mineral comercializadas em embalagem de $20 \mathrm{~L}$, no município de Marabá-Pará.

\section{Material e Métodos}

\section{Coleta das Amostras}

Foram coletadas amostras de água mineral $(100 \mathrm{~mL})$, de três diferentes marcas, obtidas a partir de embalagens de $20 \mathrm{~L}$. De cada marca, foram coletadas quatro amostras de água, totalizando doze amostras. Na escolha das marcas a serem avaliadas, levou-se em consideração as marcas de maior consumo pela população do município de Marabá-Pará.

As amostras foram acondicionadas em caixa de isopor com gelo e enviadas ao Laboratório de Físico-Química e de Microbiologia, do Núcleo de Marabá, da Universidade do Estado do Pará UEPA.

\section{Análises físico-químicas}

As análises físico-químicas das marcas de água mineral foram realizadas no Laboratório de Química e no Laboratório de Alimentos, do Núcleo de Marabá, da Universidade do Estado do Pará - UEPA. As análises foram: $\mathrm{pH}$, alcalinidade, dureza total, cor, cloretos, sólidos totais e turbidez. Todas as análises foram realizadas em triplicata e seguiram a metodologia preconizada por Instituto Adolpho Lutz (2005).

Para a determinação de $\mathrm{pH}$, utilizou-se o pHmetro de marca Quimis, modelo Q-400A. Para a determinação de alcalinidade, utilizou-se $50 \mathrm{~mL}$ da amostra e adicionou-se 3 gotas de verde de bromocresol/vermelho de metila. Fez-se a titulação com ácido sulfúrico 0,02 $\mathrm{N}$ até a mudança da cor azul-esverdeada para róseo; ao término anotou-se o volume total de $\mathrm{H}_{2} \mathrm{SO}_{4}$ gasto em $\mathrm{mL}$.

Na determinação de dureza, utilizou-se $50 \mathrm{~mL}$ da amostra transferida para um Erlenmeyer. Adicionou-se $1 \mathrm{~mL}$ da solução-tampão e uma pequena porção $(0,05 \mathrm{~g})$ do indicador negro de eriocromo T. Titulou-se com a solução de EDTA 0,01 M até que a coloração púrpura passe a azul.

Para se determinar a cor, preparou-se padrões de cor na faixa de 5 a 50 unidades de cor, medindo 0,$5 ; 1,0 ; 1,5 ; 2,0 ; 2,5 ; 3,0 ; 3,5 ; 4,0 ; 4,5 ; 5,0 ; 6,0$ e 7,0 $\mathrm{mL}$ da solução padrão Cloroplatinato de Potássio, e colocou-se em tubos de Nessler de $50 \mathrm{~mL}$. Em seguida diluiu-se com água destilada até a marca de $50 \mathrm{~mL}$; mediu-se $50 \mathrm{~mL}$ da amostra em outro tubo de Nessler e comparou com os padrões. 
Na determinação de cloretos, utilizou-se $100 \mathrm{~mL}$ de amostra, e adicionou- se uma pequena porção de carbonato de cálcio $\left(\mathrm{CaCO}_{3}\right)$ e 3 a 4 gotas de cromato de potássio ( $\left.\mathrm{K} 2 \mathrm{CrO} 45 \%\right)$. Titulou-se com nitrato de prata (AgNO3 0,01 mol/L) até viragem de amarelo para vermelho-tijolo (SILVA et al., 2008).

A determinação de sólidos totais foi realizada em estufa, a $105{ }^{\circ} \mathrm{C}$, por 3 horas. Para a determinação da turbidez foi utilizado método Nefelométrico, com aparelho Turbidímetro modelo Ap. 1000, sendo que a leitura é dada em NTU (Unidade Nefelométrico de Turbidez).

\section{Análises microbiológicas}

As análises microbiológicas das marcas de água mineral foram realizadas no Laboratório de Microbiologia, do Núcleo de Marabá, da Universidade do Estado do Pará - UEPA. As análises foram: coliformes termotolerantes e totais, Pseudomonas aeruginosa e Clostrídios sulfito redutores. Todas as análises foram realizadas em triplicata e seguindo os métodos analíticos oficiais exigidos pelo Ministério da Agricultura, e Agência Nacional de Vigilância Sanitária - ANVISA, Resolução $\mathrm{n}^{\mathrm{o}}$ 12, de 2 de janeiro de 2001 (BRASIL, 2001).

A determinação de coliformes termotolerantes e coliformes totais foi realizada pela técnica dos tubos múltiplos $\left(10^{-1}, 1\right.$ e 10). Empregou-se, como meio presuntivo, o Caldo Lauril Sulfato Triptose, com incubação a $35^{\circ} \mathrm{C}$, por 48 horas. Após leitura, os tubos positivos foram repicados para Caldo Verde Brilhante bile, a $2 \%$ de lactose, para confirmação da presença de coliformes totais, e repicados para “Caldo EC", visando à confirmação de coliformes termotolerantes.

O método para determinação de Pseudomonas Aeruginosa baseou-se na filtração de $100 \mathrm{~mL}$ da amostra, através da membrana filtrante com porosidade. As bactérias retidas na membrana foram transferidas para o meio de cultura nutritivo, seletivo e diferencial (meio Agar-mPA-B). As placas foram incubadas à temperatura de $41,5^{\circ} \mathrm{C}$ por 48 horas. As colônias típicas com coloração marromescuras ou pretas esverdeado, com núcleo central e bordas mais claras espraiadas, foram contadas, utilizando-se microscópio estereoscópico. A partir destas colônias típicas calculou-se a densidade. Para a realização do teste confirmativo, colhe-se um inóculo da colônia e depositou-se em um ponto das bordas da placa contendo ágar leite, em incubação sob $35^{\circ} \mathrm{C}$, por 48 horas. Após esse tempo, efetuou-se a leitura, considerando como colônias típicas as que hidrolisam a caseína e produzem pigmentos verdes, difusível no meio de cultura.

Para a determinação de Clostridium Sulfito Redutores utilizou-se a técnica dos tubos múltiplos. $100 \mathrm{~mL}$ das amostras foram aquecidas em banho-maria a $75{ }^{\circ} \mathrm{C}$ por 10 minutos, para eliminação de organismo não esporulados e formas vegetativas, em seguida ocorrendo a filtração. Foi adicionado $0,2 \mathrm{~mL}$ de citrato férrico à $7 \%$ e $0,2 \mathrm{~mL}$ de sulfito de sódio à $4 \%$ a cada tubo contendo o meio SPS, e incubados em jarra de anaerobiose, sob temperatura de $35^{\circ} \mathrm{C}$, por 48 horas. 
Efetuou-se a leitura considerando resultado positivo para tubos que apresentaram enegrecimento do meio de cultura. Os tubos com coloração densa com turvação do meio de cultura são considerados resultados duvidosos, devendo ser submetido à contraprova.

\section{Resultado e Discussões}

Caracterização físico-química das amsotras de água mineral

As médias dos resultados das análises físico-químicas das marcas de água mineral, comercializadas em Marabá-Pará, estão apresentadas na Tabela 1.

Tabela 1 - Resultado das médias das análises físico-químicas das marcas de água mineral

\begin{tabular}{cccc}
\hline Determinações & \multicolumn{3}{c}{ Marcas de Água Mineral } \\
\cline { 2 - 4 } & $\mathbf{A}$ & $\mathbf{B}$ & $\mathbf{C}$ \\
\hline $\mathrm{pH}$ & $5,20 \pm 0,10$ & $4,63 \pm 0,02$ & $6,29 \pm 0,10$ \\
Alcalinidade (mg/L) & $16,60 \pm 0,01$ & $36,00 \pm 0$ & $36,00 \pm 0$ \\
Dureza Total (mg/L) & $13,00 \pm 2$ & $8,30 \pm 1,15$ & $11,00 \pm 3,60$ \\
Turbidez (UT(4)) & 0,00 & 0,00 & $0,80 \pm 0,90$ \\
Sólidos Totais (mg/L) & $29,30 \pm 0,07$ & $56,30 \pm 0,10$ & $66,30 \pm 0$ \\
Cor (UH(2)) & Ausência & Ausência & Ausência \\
Cloretos (mg/L) & $25,90 \pm 10,83$ & $25,90 \pm 10,83$ & $30,70 \pm 10,83$ \\
\hline
\end{tabular}

As médias dos resultados obtidos em relação ao pH das marcas A e B apresentam-se fora dos padrões estabelecidos pela legislação, que de acordo com a Portaria 1469, do Ministério da Saúde (FUNASA, 2001), o valor tem que ser de 6,0 a 9,5 para abastecimento público. A marca C apresentou-se dentro dos valores permitidos pela legislação. A marca B, com média de 4,63, teve o valor mais baixo, comparada com as demais amostras, o que evidencia uma água bastante ácida para consumo humano. Em água com $\mathrm{pH}$ abaixo de 4,6, a acidez é denominada mineral, devido à presença de ácidos minerais, provenientes provavelmente da poluição industrial ou do metabolismo microbiano (ANDRADE, 2008). Moreira (2005) encontrou valores de pH para amostras de águas de Santa Maria- RS, com níveis de 5,21 a 5,88, ficando também fora dos limites permitidos para a legislação vigente. Dias et al. (2012) ao analisar quatro marcas de água mineral comercializadas em Teresina- PI, observram níveis variando de 5,27 e 5,32, estando abaixo do valor mínimo permitido. Por outro lado, Leite et al. (2012), encontraram resultados para pH permitidos pela legislação, de aproximadamente 7, em amostras de água coletadas no Vale do Paraíba.

A marca A obteve média de 16,60 mg/L para a alcalinidade, e as marcas B e C obtiveram média de 36,00 mg/L. Não existe valores mínimos e máximos estabelecidos para este parâmetro. Entretanto, em concentrações moderadas não há restrição ao consumo, mas em concentrações elevadas podem conferir sabor desagradável. A alcalinidade da água é fundamentalmente devida a 
hidróxidos, carbonatos e bicarbonatos, correspondendo às três principais formas de alcalinidade. Habitualmente, em águas naturais, a alcalinidade, devido a presença do carbonato de cálcio $\left(\mathrm{CaCO}_{3}\right)$, varia entre $10 \mathrm{mg} / \mathrm{L}$ e $350 \mathrm{mg} / \mathrm{L}$ (PEIXOTO, 2008).

As médias obtidas de dureza para as marcas A, B e C foram de 13,00 mg/L, 8,30 mg/L e $11,00 \mathrm{mg} / \mathrm{L}$, respectivamente, sendo assim classificadas como águas moles ou brandas. De acordo com Brasil (2004), todas as amostras estavam dentro dos padrões de potabilidade por ela estabelecidos, que é de até $500 \mathrm{mg} / \mathrm{L}$. Morgano et al. (2002) observaram teores de dureza maiores que $60 \mathrm{mg} / \mathrm{L}$, sendo portanto classificadas como moderadamente duras (60 a $120 \mathrm{mg} / \mathrm{L} \mathrm{CaCO}_{3}$ ). Casalli (2008) encontrou valores variando de 5,9 mg/L a $129 \mathrm{mg} / \mathrm{L}$ em amostras obtidas em escolas e comunidades rurais na região do Rio Grande do Sul.

Os resultados obtidos para a análise de turbidez foram de 0 para as marcas A e B, e 0,80 para a amostra C, encontrando-se assim dentro dos padrões estabelecidos pela RDC $\mathrm{n}^{\circ} 54$ (BRASIL, 2004), que estabelece valor máximo de até 3,0 uT. Fard (2007) encontrou valores de turbidez com média de 0,29 uT para amostras de água mineral.

As médias para Sólidos Totais encontradas foram de 29,30, 56,30 e 63,30 mg/L para as marcas A, B e C, respectivamente. Todos os resultados obtidos encontraram-se dentro dos padrões estabelecidos pela Portaria 1469, da FUNASA, que permite um valor máximo de 1,000 mg/L.

No que se refere à avaliação da cor das marcas de águas minerais, observou-se que as mesmas são incolores, estando assim dentro dos padrões estabelecidos pela legislação que estabelece o valor máximo de 5 uH (BRASIL, 2000). Segundo a Portaria 518/MS a cor não deve ser superior à $15 \mathrm{uH}$ (SABESP, 2008). Leite et al. (2012) encontraram resultado semelhante para amostra de águas no Vale do Paraíba, onde o teste de cor mostraram que as amostras analisadas apresentaram-se incolores, sem coloração de ferrugem ou de sujidades oriundas da tubulação.

Os valores médios obtidos para cloretos foram $25,90,25,90$ e $30,70 \mathrm{mg} / \mathrm{L}$ para as marcas A, B e C, respectivamente. Todas as amostras analisadas apresentaram-se dentro dos padrões da legislação, que estabelece um valor máximo de $250 \mathrm{mg} / \mathrm{L}$, segundo a Portaria no 1469 (FUNASA, 2001). Ao avaliar a qualidade de águas minerais comercializadas em Teresina, Dias et al. (2012) verificaram níveis variados $(8,39,29,21$ e $23,80 \mathrm{mg} / \mathrm{L})$, porém dentro dos padrões estabelecidos. Nas águas tratadas, a adição de cloro puro ou em solução, leva a uma elevação do nível de cloreto, resultante das reações de dissociação do cloro na água. A concentração de cloreto em águas de abastecimento público constitui um padrão de aceitação, já que provoca sabor "salgado" na água.

\section{Caracterização microbiológica das marcas de água mineral}

As médias dos resultados das análises microbiológicas das marcas de água mineral, comercializadas em Marabá-Pará, estão apresentadas na Tabela 2. 
Tabela 2 - Resultado das médias das análises microbiológicos das marcas de água mineral

\begin{tabular}{cccc}
\hline Micro-organismos & \multicolumn{3}{c}{ Marcas de Água Mineral } \\
analisados & A & B & C \\
\cline { 2 - 4 } Coliformes Termotolerantes & Ausência & Ausência & Ausência \\
Coliformes Totais & Ausência & Ausência & Ausência \\
Clostridium sulfito redutores & Ausência & Ausência & Ausência \\
Pseudomonas aeroginosas & Ausência & Ausência & Ausência \\
\hline
\end{tabular}

Os resultados dos parâmetros microbiológicos demonstraram que as marcas analisadas, encontram-se dentro dos padrões de qualidade prevista para o consumo humano. Segundo a resolução RDC no 275, de 22 de setembro de 2005, da ANVISA, pertinente a qualidade de água mineral, para que a mesma não represente risco à saúde do consumidor, recomenda-se que não haja contaminação de coliformes termotolerantes, Enterococcus, Pseudomonas aeruginosa e Clostridios Sulfito Redutores (BRASIL, 2005).

Em avaliação da qualidade microbiológica de 70 amostras de águas minerais comercializadas em São Luís- MA, Nascimento et al. (2000) verificaram que $50 \%$ das amostras analisadas não apresentavam contaminação por coliformes totais, termotolerantes e Pseudomonas aeruginosa acima dos padrões permitidos. Entretanto, as demais encontravam-se impróprias para o consumo humano. Sant'ana et al. (2003), também obtiveram os resultados semelhantes ao avaliar 70 amostras de água minerais consumidas em São Luís - MA, onde $50 \%$ das amostras apresentavam-se impróprias em relação a esses micro-organismos. A preocupação com a presença de $P$. aeruginosa em águas minerais, reside no fato de muitas espécies serem resistentes a antibióticos, sua alta capacidade de multiplicação em águas com reduzido conteúdo de nutrientes e pelo fato de ser um patógeno oportunista com capacidade de causar infecções em indivíduos imunocomprometidos, além de poderem alterar cor, turbidez e sabor de águas (FARACHE FILHO e DIAS, 2008).

Farache Filho e Dias (2008) analisaram água mineral em galões de 20 litros em Araraquara e verificaram que $15,5 \%$ das marcas avaliadas apresentaram positividade para coliformes totais. Alves et al. (2002), em Marília-SP, verificaram a presença de coliformes totais em dezoito marcas de água mineral. Guimarães (2006), avaliando 15 marcas em Goiânia, observou que todas as marcas apresentaram contaminação por coliformes totais, e $30 \%$ por coliformes termotolerantes e por Pseudomonas aeruginosa.

Por outro lado, Silva et al. (2008), não observaram contaminação por nenhum microorganismo em 10 marcas de água mineral em João Pessoa-Paraíba. Reis et al. (2006) também não verificaram contaminação por coliformes totais e termotolerantes em amostras de águas minerais de São José do Rio Preto-SP. Segundo Andrade (2008), a presença de coliformes na água mineral pode indicar ausência de cuidados sanitários, problemas nas operações de captação, canalização, 
filtração, envasamento ou outros que possam alterar as propriedades características e a composição das mesmas.

\title{
4 Conclusão
}

As três marcas de água minerais apresentaram-se dentro dos padrões físico-químicos (alcalinidade, dureza, sólidos totais, turbidez, cor e cloreto). As marcas classificaram-se como água mole ou brandas, no que se refere à dureza. Todas as marcas foram definidas como incolores. Porém, as marcas A e B apresentaram-se fora dos padrões de qualidade no que se refere aos níveis de $\mathrm{pH}$, ficando somente a marca dentro dos valores permitidos pela legislação.

As análises microbiológicas permitam verificar que todas as marcas avaliadas encontraramse dentro dos padrões oficiais, sendo assim adequada ao consumo humano.

\begin{abstract}
Mineral waters coming from underground sources is that originate through the infiltration of water into the soil from the surface, which is enriched in mineral salts. Must submit physic-chemical characteristics and microbiological quality suitable for human consumption and is considered of paramount importance for health. There is great concern among consumers about the quality of water that is consumed. This study aimed to evaluate the physico-chemical (pH, alkalinity, total hardness, turbidity, total solids, chlorides and color) and microbiological characteristics (total coliforms, fecal coliforms, Pseudomonas and Clostridium sulphite reducing aeroginosas) of three brands of mineral water sold in the city of Maraba, Para. The results of physico-chemical analyzes showed that the water samples are within the standards established by the legislation. However, samples $A$ and $B$ were considered to be deprecated in relation to the $\mathrm{pH}$ level, with values of 5.20 and 4.63, respectively. The microbiological results identified that all watermarks are within the microbiological standards established by law, with the absence of all micro-organisms assessed.
\end{abstract}

Key-words: mineral water, quality, healthcare.

\section{Referências}

ALVES, N. C.; ODORIZZI, A. C.; GOULART, F. C. Análise microbiológica de águas minerais e de água potável de abastecimento, Revista Saúde Pública, v. 36, n. 6, p. 749-751, 2002. http://dx.doi.org/10.1590/S003489102002000700014 .

ANDRADE, N. J. Higiene na indústria de alimentos: avaliação e controle da adesão e formação de biofilmes bacterianos. São Paulo: Varela, 2008.

BRAnCO, S. M. Água, Meio Ambiente e Saúde. Águas Doces no Brasil. São Paulo: Escrituras Editora, p. $227,248$. 1999.

BRASIL, Agência Nacional de Vigilância Sanitária- ANVISA. Resolução- RDC n 54, de 15 de junho de 2000. "Regulamento Técnico para Fixação de Identidade e Qualidade de Água Mineral Natural e Água Natural". disponível em <http://www.anvisa.gov.br/legis/resol/2000/54_00rdc.htm>, acesso em fevereiro de 2012.

BRASIL, Agência Nacional de Vigilância Sanitária - ANVISA. Resolução - RDC n 275, de 23 setembro de 2005. "Regulamento Técnico das Características Microbiológicas para Água Mineral Natural e Água Natural”. disponível em <http.www.anvisa.gov.br>, acesso em fevereiro de 2012. 
BRASIL. Ministério da Saúde. Agência Nacional de Vigilância Sanitária. Resolução RDC no 274, de 22 de setembro de 2005. Aprova o Regulamento Técnico para águas envasadas e gelo.

BRASIL. Ministério da Saúde. Portaria no 518 de 25 de março de 2004. Dispõe sobre os Procedimentos e responsabilidade relativos ao controle e vigilância da qualidade da água para consumo humano e seu padrão de potabilidade. Brasília: Ministério da Saúde, 2004.

BRASIL, Agência Nacional de Vigilância Sanitária - ANVISA. Resolução - RDC n. 12, de 2 de janeiro de 2001. Ministério da Saúde, 2001.

CASALLI. C. A. Qualidade da água para consumo humano ofertada em escolas e comunidades rurais da região central do Rio Grande do Sul. Dissertação (Mestrado em Ciências do Solo) Universidade Federal de Santa Maria, 173 p, fevereiro 2008.

DIAS, L. P.; MACÊDO, J. S. R.; SOUSA, A. L.; CRONEMBERGER, M. G. O. Características físico-químicas de quatro marcas de água mineral comercializadas em Teresina-PI. CONNEPI 2010, disponível em : <http:

http://connepi.ifal.edu.br/ocs/index.php/connepi/CONNEPI2010/paper/view/651/390>

FARACHE FILHO, A.; DIAS, M. F. F. Qualidade microbiológica de águas minerais em galões de 20 litros. Alimentos e Nutrição. v.19, n. 3, p. 243-248, 2008.

FARD, E. M. G. P. Avaliação da qualidade da água mineral e do processo de envase em duas fontes comerciais. 2007. 109p. Dissertação (Mestrado em Tecnologia de Alimentos) - Setor de Tecnologia de Alimentos, da Universidade Federal do Paraná, 2007.

FUNASA. Fundação Nacional de Saúde. Portaria no 1.469/2000, de 29 de dezembro de 2000. Aprova o controle e vigilância da qualidade da água para consumo humano e seu padrão de potabilidade. Brasília: Fundação Nacional de Saúde, 2001. 32 p.

GUIMARÃES, A. P. R. C. 2006. Avaliação Microbiológica de amostras de água mineral natural, sem gás, envasadas, comercializadas em Goiânia-GO. Instituto de Patologia Tropical e Saúde Pública da Universidade Federal de Goiás.

INSTITUTO ADOLFO LUTZ. Normas Analíticas do Instituto Adolfo Lutz. Métodos químicos e físicos para análise de alimentos, 3. ed. São Paulo: IMESP, 2008. p. 304

LEITE, A.; BELO, R. A. S.; KHOURI, S.; ARAKAWA, S. Análise físico-química e microbiológica da qualidade da água de diversas localidades da Universidade do Vale do Paraíba.IN: XIII Encontro Latino Americano de Iniciação Científica e IX Encontro Latino Americano de Pós-Graduação, 2012. Anais... Paraíba, p.1- 4, 2012.

MACÊDO, J. A. B. Águas \& Águas. São Paulo: Livraria varela, 2001.

MOREIRA, C. M. D. Aspectos qualitativos da água subterrânea no campus da UFSM. Dissertação (Mestrado do Programa de Pós-Graduação em Engenharia Civil) Área de Concentração em Recursos Hídricos e Saneamento Ambiental, da Universidade de Santa Maria, 2005.

MORGANO, M. A.; SCHATTI, A. C.; ENRIQUES, H. A.; MANTOVANI, D. M. B. Avaliação físico-química de águas minerais comercializadas na região de Campinas. Ciência e Tecnologia dos Alimentos, v. 22, n. 3, p. 239-243, 2002 .

NASCIMENTO, A. R. et al. Qualidade microbiológica das águas minerais consumidas na cidade de São Luís- MA. Higiene Alimentar, v. 14, n. 76, p. 69-72, 2000.

PEIXOTO, J. Laboratórios de tecnologias ambientais análises físico-químicas cor, turbidez, ph, temperatura, alcalinidade e dureza. MIEB - 2008.

POMPEU, C. T. Direito de águas no Brasil. 2 ed. São Paulo: Editora Revista dos Tribunais, 2010.

REIS, M. M. Fontes naturais: vantagens de uma captação correta. Revista Engarrafador Moderno, São Paulo, n. 60, p. 53-56, out. 1998 .

RICHTER, C. A.; NETO, J. M. de A. Tratamento de água. 1. ed. São Paulo: Edgard Blucher Ltda, 1991. 332p.

SABESP. Disponível em < www.sabesp.com.br > Acesso em: 22 de abril de 2012. 
SANT'ANA, A. S.; SILVA, S. C. F. L.; FARANI, I. O. Jr.; AMARAL, C. H. R.; MACEDO, V. F. Qualidade microbiológica de águas minerais. Ciência e Tecnologia de Alimentos, v. 23, Supl, p. 190-194, 2003..

SILVA, V. P. FERREIRA, D. N.; RAMOS, N. P.; SIllVIRA, E. O.; BRITO, G. A. P.; CABRAL, T. M. A; NASCIMENTO, G. J. Estudo da qualidade microbiológica de 10 amostras de água mineral natural envasada por uma empresa de mineração da cidade de João Pessoa-PB. In: XI Encontro de Iniciação à Docência, 2008. Anais... João Pessoa, p. 1-5, 2008.

Submetido em 29 out 2012, Aceito para publicação em 16 jul. 2013. 